${ }^{1}$ Internal Medicine, and

Rheumatology, Clinical Immunology and Allergy, University of Crete

School of Medicine, Heraklion,

Greece; ${ }^{2}$ Clinical Trials and Evidence-

Based Medicine Unit, Department of

Hygiene and Epidemiology, University

of Ioannina School of Medicine,

Ioannina, Greece; ${ }^{3}$ Department of

Nephrology and Transplantation

Medicine, Laiko Hospital, Athens,

Greece; ${ }^{4}$ Cattedra di Reumatologia

Universita di Pisa, Pisa, Italy;

${ }^{5}$ Department of Autoimmune

Diseases, Hospital Clinic, Barcelona,

Spain; ${ }^{6}$ Institute of Rheumatology,

Prague, Czech Republic;

Department of Rheumatology,

Rikshospitalet, Oslo, Norway;

${ }^{8}$ Rheumatology Department,

Université catholique de Louvain,

Cliniques Universitaires Saint-Luc,

Brussels, Belgium; ${ }^{9}$ Department of

Rheumatology Leiden University

Medical Center, Leiden, The

Netherlands; ${ }^{10}$ Centre for

Rheumatology, University College

London Hospitals, London, UK.

Department of Clinical

Immunology, University Medical

Center Groningen, Groningen, The

Netherlands: ${ }^{12}$ Lupus Research Unit,

The Rayne Institute, St Thomas'

Hospital, London, UK; ${ }^{13}$ Service de

Médecine Interne, Groupe Hospitalier

Pitié-Salpêtrière, Paris, France;

${ }^{14}$ Rheumatolology, Clinic of

Endocrinology, Diabetology and

Rheumatology, Heinrich-Heine-

University, Dusseldorf, Germany;

${ }^{15}$ Department of Rheumatology,

Medical University of Vienna, Austria;

${ }^{16}$ Department of Rheumatology,

University Hospital of Lund, Lund,

Sweden; ${ }^{17}$ Rheumatologia e

Immunologia Clinica, Ospedale Civile

di Brescia, Italy; ${ }^{18}$ Rheumatology

Unit, Department of Medicine,

Karolinska Institutet, Karolinska

University Hospital, Solna, Sweden;

${ }^{19}$ Centre for Immune Regulation,

Division of Immunity and Infection,

The University of Birmingham,

Birmingham, UK

Correspondence to:

D T Boumpas, Departments of Internal Medicine and

Rheumatology, University of

Crete School of Medicine,

71003, Heraklion, Greece;

boumpasd@med.uoc.gr

This is an abbreviated version of the recommendations. The fulltext version is available online (http://ard.bmj.com)

Dr Font died on 26 July 2006.

Accepted 30 April 2007

Published Online First 5 July 2007

This paper is freely available online under the BMJ Journals unlocked scheme, see http:// ard.bmj.com/

info/unlocked.dtl

\title{
EULAR recommendations for the management of systemic lupus erythematosus. Report of a Task Force of the EULAR Standing Committee for International Clinical Studies Including Therapeutics
}

\author{
G Bertsias, ${ }^{1} \mathrm{~J}$ P A loannidis, ${ }^{2} \mathrm{~J}$ Boletis, ${ }^{3}$ S Bombardieri, ${ }^{4} \mathrm{R}$ Cervera, ${ }^{5} \mathrm{C}$ Dostal, ${ }^{6} \mathrm{~J}$ Font, ${ }^{5}$ \\ I M Gilboe, ${ }^{7} \mathrm{~F}$ Houssiau, ${ }^{8}$ T Huizinga, ${ }^{9} \mathrm{D}$ Isenberg, ${ }^{10} \mathrm{C} \mathrm{G}$ M Kallenberg, ${ }^{11}$ \\ M Khamashta, ${ }^{12} \mathrm{~J}$ C Piette, ${ }^{13} \mathrm{M}$ Schneider, ${ }^{14} \mathrm{~J}$ Smolen, ${ }^{15} \mathrm{G}$ Sturfelt, ${ }^{16}$ A Tincani, ${ }^{17}$ \\ $\mathrm{R}$ van Vollenhoven, ${ }^{18} \mathrm{C}$ Gordon, ${ }^{19} \mathrm{D}$ T Boumpas ${ }^{1}$
}

\section{ABSTRACT}

Objective: Systemic lupus erythematosus (SLE) is a complex disease with variable presentations, course and prognosis. We sought to develop evidence-based recommendations addressing the major issues in the management of SLE.

Methods: The EULAR Task Force on SLE comprised 19 specialists and a clinical epidemiologist. Key questions for the management of SLE were compiled using the Delphi technique. A systematic search of PubMed and Cochrane Library Reports was performed using McMaster/Hedges clinical queries' strategies for questions related to the diagnosis, prognosis, monitoring and treatment of SLE. For neuropsychiatric, pregnancy and antiphospholipid syndrome questions, the search was conducted using an array of relevant terms. Evidence was categorised based on sample size and type of design, and the categories of available evidence were identified for each recommendation. The strength of recommendation was assessed based on the category of available evidence, and agreement on the statements was measured across the 19 specialists.

Results: Twelve questions were generated regarding the prognosis, diagnosis, monitoring and treatment of SLE, including neuropsychiatric SLE, pregnancy, the antiphospholipid syndrome and lupus nephritis. The evidence to support each proposition was evaluated and scored. After discussion and votes, the final recommendations were presented using brief statements. The average agreement among experts was 8.8 out of 10 .

Conclusion: Recommendations for the management of SLE were developed using an evidence-based approach followed by expert consensus with high level of agreement among the experts.

Approximately half a million people in Europe and a quarter of a million people in the USA (projections based on prevalence rates of $30-50$ per 100 000) have systemic lupus erythematosus (SLE). ${ }^{1}$ The great majority of these patients are women in their childbearing years. SLE is a complex disease with variable presentations, course and prognosis characterised by remissions and flares. $^{23}$ Because of the systemic nature of the disease, multiple medical specialties are involved in the care of these patients. To avoid fragmentation and optimise management, there is a presently unmet need to establish an integrated approach based on widely accepted principles and evidencebased recommendations.

Recommendations and/or guidelines represent a popular way of integrating evidence-based medicine to clinical practice. These are systematically developed statements to assist practitioner and patient decisions about appropriate healthcare for specific clinical circumstances. ${ }^{4}$ To this end and under the auspices of EULAR, we undertook the task of developing guidelines for the management of various aspects of SLE. To ensure a high level of intrinsic quality and comparability of this approach, we used the EULAR standard operating procedures. ${ }^{5}$ We present here 12 key recommendations, selected from a panel of experts, for the management (diagnosis, treatment, monitoring) of SLE using a combination of research-based evidence and expert consensus.

\section{METHODS}

The EULAR standardised operating procedures suggest a discussion among experts in the field about the focus, the target population and an operational definition of the term "management", followed by consensus building based on the currently available literature (evidence-based), combined with expert opinion, as needed, to arrive at consensus for a set of recommendations. ${ }^{5}$ The expert committee agreed on 12 topics, including general management of SLE (5 questions), neuropsychiatric lupus (2 questions), pregnancy in lupus (1 question), antiphospholipid syndrome (1 question) and lupus nephritis (3 questions). A systematic search of PubMed the Cochrane library was performed, and retrieved items were screened for eligibility based on their title, abstract and/or full content. Evidence was categorised according to study design using a traditional rating scale, and the strength of the evidence was graded combining information on the design and validity of the available data (see the full-text version for more details). The results of the literature search were summarised, aggregated and distributed to the expert committee. Following discussion, voting and adjusting the formulation, the expert committee arrived at 12 final recommendations for the management of SLE (table 1). 
Further, the expert committee proposed topics for a Research Agenda.

\section{RESULTS (TABLES 1 AND 2) Prognosis}

SLE runs a highly variable clinical course, and determination of prognosis together with the development of reliable indicators of active disease, disease severity and damage accrual is important. Several clinical manifestations (discoid lesions, ${ }^{6}$ arthritis, ${ }^{7}$ serositis, ${ }^{8}$ renal involvement, ${ }^{910}$ psychosis or seizures $^{611}$ ), laboratory tests (anaemia, ${ }^{12}{ }^{13}$ thrombocytopenia, ${ }^{14}$ leucopenia, ${ }^{15}$ serum cretatinine ${ }^{9}$ ), immunological tests (antidsDNA, ${ }^{10}{ }_{14}^{16}$ anti-C1q, ${ }^{17}$ antiphospholipid, ${ }^{18-20}$ anti-RNP, ${ }^{18}$ antiRo/SSA, ${ }^{21} 22$ anti-La/SSB antibodies, ${ }^{23}$ serum complement concentrations ${ }^{12}{ }^{1423}$ ), brain $\mathrm{MRI}^{7}$ and renal biopsy ${ }^{24}{ }^{25}$ correlate with outcome in terms of development of major organ involvement (nephritis, neuropsychiatric lupus), end-stage renal disease (ESRD), and damage accrual or decreased survival.

The small size and large number of candidate predictors tested represent significant problems and raise the possibility for selective reporting of significant associations. Moreover, these prognostic variables have not been uniformly informative across

Table 1 Summary of the statements and recommendations on the management of systemic lupus erythematosus based on evidence and expert opinion

\section{General management}

Prognosis

In patients with SLE, new clinical signs (rashes, arthritis, serositis, neurological manifestations and seizures/psychosis), routine laboratory (CBC, serum creatinine, proteinuria and urinary sediment), and immunological tests (serum C3, anti-dsDNA, anti-Ro/SSA, anti-La/SSB, antiphospholipid, anti-RNP), may provide prognostic information for the outcome in general and involvement of major organs, and thus should be considered in the evaluation of these patients. Confirmation by imaging (brain MRI), and pathology (renal biopsy) may add prognostic information and should be considered in selected patients.

Monitoring

New clinical manifestations such as number and type of skin lesions, or arthritis, serositis, and neurological manifestations (seizures/psychosis), laboratory tests (CBC),

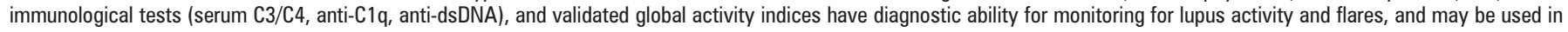
the monitoring of lupus patients.

Co-morbidities

SLE patients are at increased risk for certain co-morbidities, due to the disease and/or its treatment. These co-morbidities include infections (urinary-tract infections, other infections), atherosclerosis, hypertension, dyslipidaemias, diabetes, osteoporosis, avascular necrosis, malignancies (especially non-Hodgkin's lymphoma). Minimisation of risk factors together with a high-index of suspicion, prompt evaluation, and diligent follow-up of these patients is recommended.

Treatment

In the treatment of SLE without major organ manifestations, antimalarials and/or glucocorticoids are of benefit and may be used. NSAIDs may be used judiciously for limited periods of time at patients at low risk for their complications. In non-responsive patients or patients not being able to reduce steroids below doses acceptable for chronic use, immunosuppressive agents such as azathioprine, mycophenolate mofetil and methotrexate should also be considered.

Adjunct therapy

Photo-protection may be beneficial in patients with skin manifestations and should be considered. Lifestyle modifications (smoking cessation, weight control, exercise) are likely to be beneficial for patient outcomes and should be encouraged. Depending on the individual medication and the clinical situation, other agents (low-dose aspirin, calcium/vitamin D, biphosphonates, statins, antihypertensives (including angiotensin converting enzyme inhibitors)) should be considered. Oestrogens (oral contraceptives, hormone-replacement therapy) may be used, but accompanying risks should be assessed.

\section{Neuropsychiatric lupus}

\section{Diagnosis}

In SLE patients, the diagnostic work-up (clinical, laboratory, neuropsychological, and imaging tests) of neuropsychiatric manifestations should be similar to that in the general population presenting with the same neuropsychiatric manifestations.

Treatment

SLE patients with major neuropsychiatric manifestations considered to be of inflammatory origin (optic neuritis, acute confusional state/coma, cranial or peripheral neuropathy, psychosis, and transverse myelitis/myelopathy) may benefit from immunosuppressive therapy.

\section{Pregnancy in lupus}

Pregnancy affects mothers with SLE and their offspring in several ways.

(a) Mother. There is no significant difference in fertility in lupus patients. Pregnancy may increase lupus disease activity, but these flares are usually mild. Patients with lupus nephritis and antiphospholipid antibodies are more at risk of developing pre-eclampsia and should be monitored more closely.

(b) Fetus. SLE may affect the fetus in several ways, especially if the mother has a history of lupus nephritis, antiphospholipid, anti-Ro and/or anti-La antibodies. These conditions are associated with an increase in the risk of miscarriage, stillbirth, premature delivery, intrauterine growth restriction and fetal congenital heart block. Prednisolone, azathioprine, hydroxychloroquine and low-dose aspirin may be used in lupus pregnancies. At present, evidence suggests that mycophenolate mofetil, cyclophosphamide and methotrexate must be avoided.

\section{Antiphospholipid syndrome}

In patients with SLE and antiphospholipid antibodies, low-dose aspirin may be considered for primary prevention of thrombosis and pregnancy loss. Other risk factors for thrombosis should also be assessed. Oestrogen-containing drugs increase the risk for thrombosis. In non-pregnant patients with SLE and APS-associated thrombosis, long-term anticoagulation with oral anticoagulants is effective for secondary prevention of thrombosis. In pregnant patients with SLE and antiphospholipid syndrome combined unfractionated or LMW heparin and aspirin reduce pregnancy loss and thrombosis and should be considered.

\section{Lupus nephritis}

\section{Monitoring}

Renal biopsy, urine sediment analysis, proteinuria, and kidney function may have independent predictive ability for clinical outcome in therapy of lupus nephritis but need to be interpreted in conjunction. Changes in immunological tests (anti-dsDNA, serum C3) have only limited ability to predict the response to treatment and may be used only as supplemental information.

Treatment

In patients with proliferative lupus nephritis, glucocorticoids in combination with immunosuppressive agents are effective against progression to end-stage renal disease. Longterm efficacy has been demonstrated only for cyclophosphamide-based regimens, which are however associated with considerable adverse effects. In short- and medium-term trials mycophenolate mofetil has demonstrated at least similar efficacy compared with pulse cyclophosphamide and a more favourable toxicity profile: failure to respond by 6 months should evoke discussions for intensification of therapy. Flares following remission are not uncommon and require diligent follow-up.

End-stage renal disease

Dialysis and transplantation in SLE have rates for long-term patient and graft-survival comparable with those observed in non-diabetic non-SLE patients, with transplantation being the method of choice. 
Table 2 Category of evidence and strength of statements

\begin{tabular}{|c|c|c|c|c|}
\hline Recommendation/item & No. of studies evaluated & Category of evidence & Strength of statement & Mean level of agreement* \\
\hline \multicolumn{5}{|l|}{ Prognosis. Prognostic value of: } \\
\hline \multicolumn{5}{|l|}{ Clinical features } \\
\hline Rashes & 4 & 4 & B & 8.6 \\
\hline Arthritis & 4 & 4 & B & 8.7 \\
\hline Serositis & 6 & 4 & $\mathrm{~B}$ & 8.6 \\
\hline Seizures/psychosis & 9 & 4 & B & 9.0 \\
\hline \multicolumn{5}{|l|}{ Laboratory findings } \\
\hline Severe anaemia & 10 & 4 & B & 8.0 \\
\hline Leucopenia/lymphopenia & 4 & 5 & C & 8.0 \\
\hline Thrombocytopenia & 15 & 4 & B & 8.0 \\
\hline Serum creatinine & 20 & 4 & B & 9.2 \\
\hline Proteinuria/urinary sediment & 24 & 4 & B & 9.3 \\
\hline $\mathrm{C} 3 / \mathrm{C} 4$ & 13 & 4 & B & 8.4 \\
\hline Anti-dsDNA & 17 & 4 & B & 8.7 \\
\hline Anti-Ro/SSA & 6 & 4 & B & 7.7 \\
\hline Anti-La/SSB & 1 & 5 & $\mathrm{C}$ & 7.7 \\
\hline Antiphospholipid & 19 & 4 & B & 8.5 \\
\hline Anti-RNP & 3 & 4 & B & 7.6 \\
\hline \multicolumn{5}{|l|}{ Imaging } \\
\hline Brain MRI & 7 & 4 & B & 8.7 \\
\hline \multicolumn{5}{|l|}{ Pathology } \\
\hline Renal biopsy & 33 & 4 & B & 9.5 \\
\hline \multicolumn{5}{|l|}{ Monitoring. Diagnostic ability of: } \\
\hline Rashes & 1 & 5 & $\mathrm{C}$ & 8.8 \\
\hline Anaemia & 1 & 4 & $\mathrm{~B}$ & 8.3 \\
\hline Lymphopenia & 1 & 4 & $\mathrm{~B}$ & \\
\hline Thrombocytopenia & 1 & 5 & C & \\
\hline $\mathrm{C} 3 / \mathrm{C} 4$ & 13 & 4 & $\mathrm{~B}$ & 8.8 \\
\hline Anti-C1q & 8 & 4 & B & 7.7 \\
\hline Anti-dsDNA & 15 & 4 & B & 8.7 \\
\hline \multicolumn{5}{|c|}{ Comorbidities. Increased risk for: } \\
\hline Infections & 13 & 5 & $\mathrm{C}$ & 8.6 \\
\hline Urinary-tract infections & 1 & 4 & B & 8.9 \\
\hline Atherosclerosis & 14 & 4 & B & 8.8 \\
\hline Hypertension & 7 & 4 & B & 9.4 \\
\hline Dyslipidaemia & 7 & 4 & $\mathrm{~B}$ & 9.2 \\
\hline Diabetes & 3 & 5 & C & 8.9 \\
\hline Osteoporosis & 6 & 5 & C & 9.1 \\
\hline Avascular necrosis & 8 & 5 & C & 8.6 \\
\hline Neoplasms & & & & 8.7 \\
\hline Non-Hodgkin's lymphomas & 6 & 4 & B & \\
\hline Other & 10 & 4 & B & \\
\hline \multicolumn{5}{|l|}{ Therapy of uncomplicated SLE } \\
\hline Antimalarials & 4 & 2 & A & 9.4 \\
\hline NSAIDs & 1 & - & D & 8.8 \\
\hline Glucocorticoids & 3 & 2 & A & 9.1 \\
\hline Azathioprine & 1 & 4 & $\mathrm{~B}$ & 9.3 \\
\hline Mycophenolate mofetil & 4 & 6 & $\mathrm{D}$ & 6.9 \\
\hline Methotrexate & 3 & 2 & A & 8.0 \\
\hline Adjunct therapy in SLE & & & & \\
\hline Photoprotection & 1 & 4 & B & 9.2 \\
\hline Smoking cessation & - & - & $\mathrm{D}$ & 9.3 \\
\hline Weight control & - & - & $\mathrm{D}$ & \\
\hline Exercise & - & - & $\mathrm{D}$ & \\
\hline Low-dose aspirin & 1 & 4 & $\mathrm{D} \dagger$ & 9.0 \\
\hline Calcium/vitamin D & 5 & 2 & $A$ & 9.2 \\
\hline Biphosphonates & 2 & 2 & $A$ & 8.5 \\
\hline Statins & - & - & $\mathrm{D}$ & 8.9 \\
\hline Antihypertensives & - & - & $\mathrm{D}$ & 8.9 \\
\hline Oral contraceptives (safe use) & 2 & 2 & $A$ & 9.1 \\
\hline Hormone-replacement therapy & 3 & 2 & $A$ & 9.1 \\
\hline
\end{tabular}


Table 2 Continued

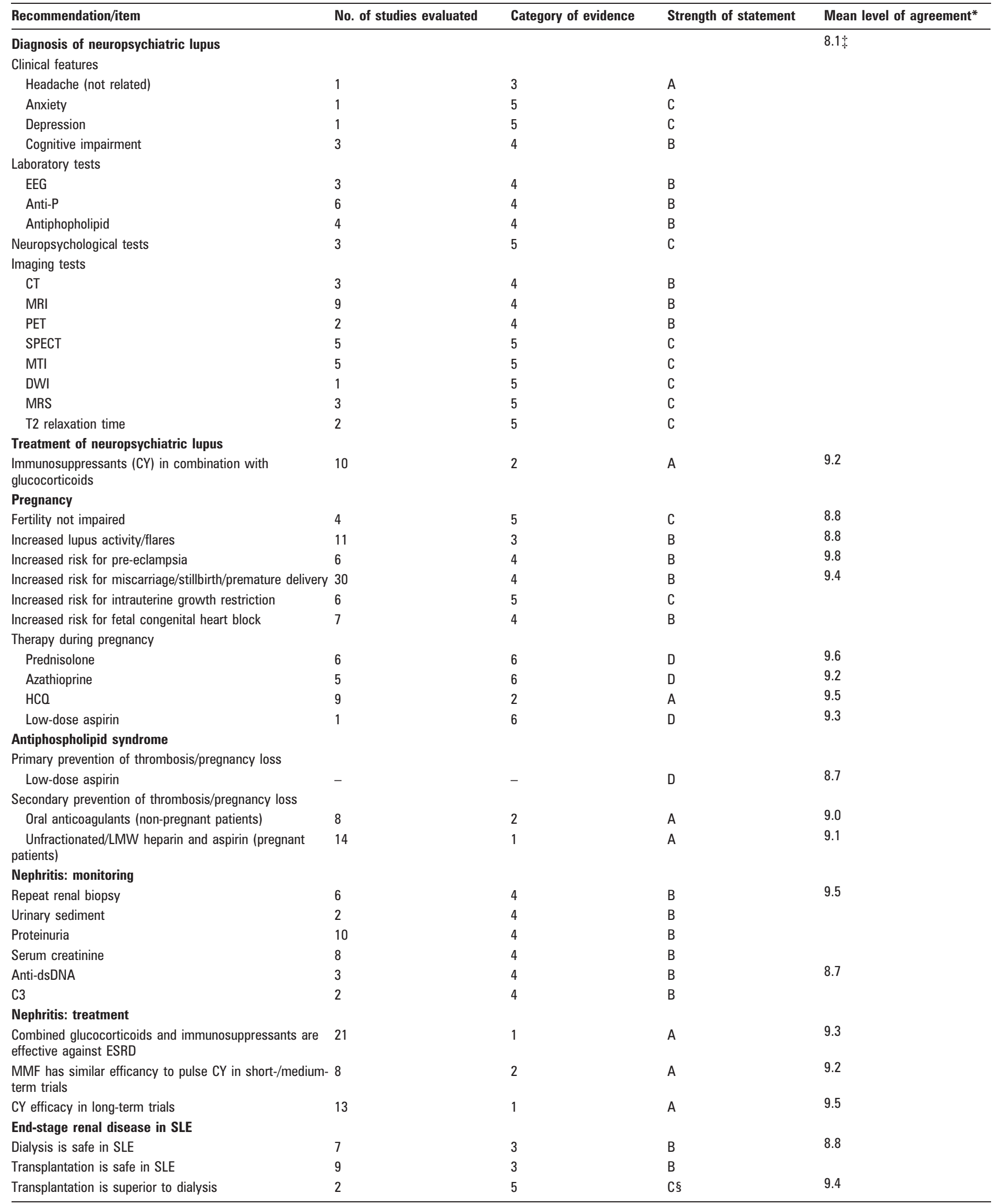

*Mean level of agreement of the Task Force members on each sub-item/statement; tin elderly SLE patients, low-dose aspirin is associated with improved cognitive function (4/B); \$this refers to the statement that "in SLE patients, the diagnostic work-up (clinical, laboratory, neuropsychological and imaging tests) of neuropsychiatric manifestations should be similar to that in the general population presenting with the same neuropsychiatric manifestations"; Snon-SLE studies. 
patients in various clinical settings or backgrounds. Most importantly, perhaps, no single predicting factor has emerged that could accurately predict the outcome. Thus, the various prognostic factors in a single patient need to be evaluated in conjunction. In general, involvement of major organs denotes a worse prognosis.

\section{Monitoring}

SLE is often complicated by exacerbations and flares of varying severity. Several global and organ-specific activity indices are used in the evaluation of SLE patients in routine clinical practice and in clinical trials. ${ }^{26-28}$ More commonly used are the British Isles Lupus Assessement Group Scale (BILAG), European Consensus Lupus Activity Measure (ECLAM), and the Systemic Lupus Erythematosus Disease Activity Index (SLEDAI). These indices have been developed in the context of long-term observational studies, are good predictors of damage and mortality, and reflect changes in disease activity. ${ }^{29-31}$ The committee encourages the use of at least one of these indices for the monitoring of disease activity. In addition, new clinical manifestations (skin lesions, ${ }^{32}$ anaemia, lymphopenia, or thrombocytopenia, ${ }^{33} 34$ low serum C3 and/or C4 concentrations, ${ }^{35}{ }^{36}$ anti-dsDNA, ${ }^{33} 37{ }^{38}$ and anti-C1q titres ${ }^{39}$ ) correlate with disease severity and can predict future flares.

While these indices and diagnostic tests may have some diagnostic ability for monitoring disease, none of them has been evaluated in randomised trials for the ability to alter management and patient outcome. The level of changes that should trigger changes in management is also unknown. For example, intensification of therapy based on serological activity alone, especially a rise in anti-dsDNA titres, ${ }^{37} 40$ runs a risk of overtreating patients, although it has been shown to prevent relapses in a randomized clinical trial (RCT). ${ }^{42}$ In these cases, most experts advise a closer follow-up for clinical disease activity.

\section{Co-morbidities}

SLE patients may be at increased risk for several co-morbidities, and treatment-related morbidity may not be easily separable from disease-related morbidity, thus raising the issue of whether the two may have an additive or synergistic effect. Patients with SLE have an almost 5-fold increased risk of death compared with the general population. ${ }^{43} 44$ Several observational cohorts and case-control studies have identified infections, ${ }^{10} 4546$ hypertension, ${ }^{47}$ dyslipidaemia, ${ }^{47}{ }^{48}$ diabetes mellitus, ${ }^{47}$ atherosclerosis ${ }^{48}{ }^{49}$ coronary heart disease, ${ }^{50}$ osteoporosis,${ }^{51}$ avascular bone necro$\operatorname{sis}^{10} 52$ and certain types of cancer (non-Hodgkin's lymphoma, lung cancer, hepatobiliary cancer $)^{53}$ as a common cause of morbidity and mortality in SLE patients. However, no randomised trials exist to suggest that intensified screening for these comorbidities would improve outcome. Moreover, many of these data originate from tertiary referral centres that usually provide care to the most severe cases of lupus raising the possibility of spectrum of disease bias. Suboptimal selection of controls may also inflate the reported strength of some of these associations. Neverthless, clinical experience and available data suggest that comorbities are a major component of the disease. The committee therefore recommends a high index of suspicion and diligent follow-up.

\section{Treatment of non-major organ involvement}

Glucocorticoids, ${ }^{42}{ }^{54}$ antimalarials, ${ }^{55} 56$ non-steroid anti-inflammatory drugs (NSAIDs) and, in severe, refractory cases, immunosuppressive agents ${ }^{57-59}$ are used in the treatment of SLE patients without major-organ involvement. Despite their widespread use, there are only a few RCTs with variable outcome criteria demonstrating their efficacy in SLE. Moreover, while most studies have shown improvement, it is not apparent whether patients were left with residual disease activity and its extent. The evidence is typically limited to small sample sizes, even when randomisation has been used. The committee recommends judicious use of these agents, taking into consideration the potential harms associated with each of these drugs.

\section{Adjunct-therapy}

In a double-blind, intra-individual comparative study, the use of sunscreens could prevent the development of skin lesions following photoprovocation. ${ }^{60}$ Although no data are available in SLE specifically, the committee felt that low-dose aspirin may be considered in adult lupus patients receiving corticosteroids, in those with antiphospholipid antibodies and in those with at least one traditional risk factor for atherosclerotic disease. ${ }^{61}$

In patients receiving long-term glucocorticoid therapy, calcium and vitamin D may protect from bone mass loss. ${ }^{6}$ Two other studies have demonstrated beneficial effects of biphosphonates in mixed population of patients with SLE and other inflammatory diseases. ${ }^{63}{ }^{64}$ Pregnancy should be postponed for 6 months after withdrawal of biphosphonates. ${ }^{65}$ Although oestrogen use has been associated with increased risk for developing SLE, ${ }^{6}$ two RCTs have concluded that oral oestrogen contraceptives do not increase the risk for flare in stable disease. ${ }^{67}{ }^{68}$ Hormone-replacement therapy results in a significantly better change in bone mass density compared with placebo or calcitriol, without increasing the risk for flares. ${ }^{69} 70$ These results may not be generalised to patients with increased risk for thombo-occlusive incidents, and accompanying risks should be assessed before oestrogen therapy is prescribed.

Despite the lack of SLE-specific literature, weight control, physical exercise and smoking cessation are recommended, especially for SLE patients with increased CVD risk. Statins and antihypertensives (ACE inhibitors) should also be considered in selected patients.

\section{Diagnosis of neuropsychiatric lupus}

Neurological and/or psychiatric manifestations occur often in SLE patients and may be directly related to disease itself (primary neuropsychiatric lupus) or to complications of the disease or its treatment (secondary neuropsychiatric lupus). There are several clinical, laboratory/immunological, neuropsychological and imaging tests ${ }^{20}{ }^{71-78}$ which have been used in SLE patients presenting with neuropsychiatric manifestations. Altogether, these studies suggest that no single clinical, laboratory, neuropsychological and imaging test can be used to differentiate neuropsychiatric systemic lupus erythematosus (NPSLE) from non-NPSLE patients with similar neuropsychiatric manifestations. A combination of the aforementioned tests may provide useful information in assessment of selected SLE patients presenting with neuropsychiatric symptoms. The diagnostic evaluation should be similar to what the evaluation would be in patients without SLE who exhibit the same neuropsychiatric manifestations.

Treatment of severe, inflammatory neuropsychiatric lupus

Primary neuropsychiatric lupus occurs in the setting of lupus activity in other organs and involves a variety of pathogenic 
mechanisms including immune-mediated neuronal excitation/ injury/death or demyelination (which is usually managed with immunosuppressive therapy) and/or ischaemic injury due to impaired perfusion (due to microangiopathy, thrombosis or emboli) commonly associated with the antiphospholipid antibodies which may require anticoagulation. ${ }^{2}$

We found a single RCT conducted in 32 SLE patients presenting with active NPSLE manifestations such as peripheral/cranial neuropathy, optic neuritis, transverse myelitis, brainstem disease or coma. ${ }^{79}$ Induction therapy with intravenous methylprednisolone (MP) was followed by either intravenous monthly cyclophosphamide (CY) versus intravenous MP every 4 months for 1 year and then intravenous CY or intravenous MP every 3 months for another year. Eighteen out of 19 patients receiving CY versus $7 / 13$ patients receiving MP ( $p=0.03)$ responded to treatment. Beneficial effects of CY in treatment of severe NPSLE have also been suggested in nonrandomised controlled studies..$^{80}$

\section{Pregnancy in lupus}

The management of a pregnant SLE patient has always been a challenge for the practising physician, since lupus may affect pregnancy and vice versa. There is not enough evidence to support a deleterious effect of SLE on fertility. ${ }^{82-84}$ Pregnancy may increase lupus disease activity and cause mild-to-moderate flares, involving mostly skin, joints and blood. ${ }^{85-87}$

Lupus nephritis ${ }^{88}{ }^{89}$ and antiphospholipid antibodies ${ }^{90} 91$ have been identified as a risk factor for hypertensive complications and pre-eclampsia. SLE patients-especially those with nephritis or antiphospholipid antibodies-are at risk for adverse pregnancy outcomes, including miscarriage, stillbirth and premature delivery (relative risks ranging from 2.2 to 5.8 ). ${ }^{87}{ }^{92-}$ ${ }_{95}$ Antiphospholipid antibodies and nephritis are also associated with low birth weight and intra-uterine growth restriction. ${ }^{96} 97$ Fetal congenital heart block is another complication of SLE pregnancies (2-4.5\%), ${ }^{98}$ and it is associated with anti-Ro/SSA or anti-La/SSB autoantibodies.

Prednisolone and other non-fluorinated glucocorticoids, azathioprine, ciclosporin A and low-dose aspirin have been used in lupus pregnancy, but their efficacy and safety have not been demonstrated in randomised trials. The efficacy and safety of hydroxychloroquine in lupus pregnancy have been evaluated in one RCT. ${ }^{100}$ These recommendations may differ from the ratings of the United States Food \& Drug Administration which, in their current form, are often not helpful for the clinician treating patients with chronic disease during pregnancy and lactation. ${ }^{65}$ There is no evidence to support the use of mycophenolate mofetil or CY, and methotrexate and these agents must be avoided during pregnancy. ${ }^{101} 102$

\section{Antiphospholipid syndrome in lupus}

Antiphospholipid antibodies are commonly encountered in SLE patients and are associated with increased risk for thromboocclusive incidents. In such patients, primary and/or secondary prevention of thrombosis is warranted, but the clinical decision is often hampered by accompanying risks for treatment-related adverse effects (ie, major bleeding). Despite the lack of evidence for primary prevention of thombosis and pregnancy loss, the expert committee recommends the use of low-dose aspirin in SLE patients with antiphospholipid antibodies, especially when other risk factors for thrombosis coexist.

The effectiveness of oral anticoagulation over aspirin alone in prevention of thrombosis in (non-pregnant) SLE patients with antiphospholipid antibodies and thrombosis has been established in retrospective controlled studies. ${ }^{103-106}$ Two RCTs ${ }^{107} 108$ have demonstrated no superiority of high-intensity (target INR 3.1-4.0) over moderate-intensity warfarin (INR 2.0-3.0) for secondary prevention, and increased risk for minor bleeding in the high-intensity $\operatorname{arm}(28 \%$ vs $11 \%) .{ }^{108}$ Their results, however, are limited in that most patients $(>70 \%)$ had history of venous-rather than arterial-thrombosis, and that patients who had already had recurrent events on oral anticoagulation were excluded. Conversely, retrospective studies including more patients with previous arterial thrombosis or stroke have concluded that high-intensity warfarin is more efficacious in secondary prevention of thrombosis without increasing the risk for major bleeding. ${ }^{103-105} 109110$ The committee proposes that in patients with APS and a first event of venous thrombosis, oral anticoagulation should target INR 2.0-3.0. In the case of arterial or recurrent thrombosis, high-intensity anticoagulation (target INR 3.0-4.0) is warranted.

As for pregnant SLE patients with APS, a recent Cochrane Review concluded that combined unfractionated heparin and aspirin may reduce the risk for pregnancy loss (RR 0.46, 95\% CI: 0.29 to 0.71$){ }^{111}$ The combination of low-molecular-weight heparin and aspirin also seems to be effective (RR 0.78, 95\% CI: 0.39 to 1.57$)$. There are no randomised trials assessing the usefulness of anticoagulation in prevention of recurrent thrombosis during pregnancy. The committee recommends the use of aspirin and heparin for the prevention of APS-related thrombosis during pregancy.

\section{Lupus nephritis: diagnosis and monitoring}

In patients with suspected lupus nephritis, renal biopsy may be used to confirm the diagnosis, evaluate disease activity, chronicity/damage, and determine prognosis and appropriate therapy. The predictive value of second renal biopsy (ie, after treatment initiation) has been assessed in one prospective ${ }^{112}$ and a few retrospective studies. ${ }^{113} 114$ It was found that some pathology findings were associated with clinical response and outcome in lupus nephritis. Nevertheless, repeat renal biopsies pose a risk to the patient and may not be feasible for all patients. There is some evidence to support the predictive ability of urine sediment analysis in monitoring lupus nephritis therapy. ${ }^{115} 116$ Changes in proteinuria, ${ }^{117}$ serum creatinine, 22 36113117 anti-dsDNA and serum C3 concentations ${ }^{36} 118119$ correlate with renal flares and outcome. It should be emphasised, however, that these studies were not specifically designed to evaluate the efficacy of various tests in monitoring response to therapy of lupus nephritis. There are no randomised trials evaluating the benefits from various monitoring strategies.

\section{Lupus nephritis: treatment}

The treatment of lupus nephritis often consists of a period of intensive immunosuppressive therapy (induction therapy) followed by a longer period of less intensive maintenance therapy. In a recent Cochrane Review, CY plus steroids reduced the risk for doubling of serum creatinine level compared with steroids alone $(R R=0.6)$, but had no impact on overall mortality. ${ }^{120}{ }^{121}$ Azathioprine plus steroids reduced the risk for all-cause mortality compared with steroids alone $(R R=0.6)$, but had no effect on renal outcomes. CY was superior to azathioprine and/or corticosteroids with high-dose, intermittent administration of CY (pulse therapy) demonstrating a more favourable efficacy-to-toxicity ratio than oral CY. ${ }^{122}$ In a long-term follow-up (median 11 years) of an RCT combination 
therapy with glucocorticoids and CY demonstrated efficacy (83\% preserved renal function), without substantially increasing the risk for adverse effects. ${ }^{123}$ Ovarian failure after CY therapy remains a considerable problem and is both dose- and agedependent. ${ }^{124}$ Gonadal protection may be feasible with the use of $\mathrm{GnRH}$ analogues, a finding that requires further confirmation. $^{125}$

The efficacy of MMF as induction therapy has been assessed in 4 RCTs, which concluded that MMF was associated with a reduced risk for treatment failure $(R R=0.7)$ and for the composite end point of death or ESRD $(R R=0.4)$ compared with CY. ${ }^{126-129}$ The usefulness of MMF as a maintenance agent has been assessed in a single RCT of 59 patients who received induction therapy with boluses of IV-CY and glucocorticoids and then were randomly assigned to IV-CY, oral azathioprine or oral MMF for 1-3 years. ${ }^{130}$ The event-free survival rate for the composite end point of death or ESRD was higher in the AZA and MMF groups than in the CY group. There was a significantly higher incidence of sustained amenorrhoea in the CY group.

The committee recommends that physicians use MMF as induction therapy for selected patients under close observation; failure to achieve a significant response by 6 months at the latest (defined as improvement of serum creatinine and reduction of proteinuria to $<1 \mathrm{~g} /$ day $^{131}$ ) should evoke discussions for intensification of therapy. For maintenance therapy, MMF can be used in patients unable to tolerate azathioprine or whose symptoms flare up while on treatment. Although data with MMF are encouraging, in the opinion of the committee the drug cannot replace at present the combination of intravenous CY with intravenous MP as the treatment of choice for severe lupus nephritis. ${ }^{123}$ Small, non-controlled trials with short follow-up suggest that up to $50 \%$ of refractory patients to CY may have a clinically significant response to rituximab, a monoclonal antibody directed against B cells. ${ }^{132}{ }^{133}$

Table 3 Research agenda

\section{Epidemiology}

Relative importance of environmental factors (exposure to sun, smoking, diet) in the pathogenesis of SLE

Incidence, prevalence, and severity of SLE in various European populations? Is there a north-to-south gradient?

Pathogenesis

Genetic factors for disease susceptibility and severity

Effector mechanisms and repair of tissue injury

Early diagnosis-primary prevention

Identification of patients at higher risk for SLE

Feasibility of primary prevention

Primary prevention of cardiovascular disease in high-risk patients (eg, aspirin, statins, others)

Initial diagnostic work-up and monitoring

Minimum diagnostic work-up for suspected SLE

Work-up for disease limited to a single organ (eg, skin, blood, others)

Diagnosis-prognosis

Diagnostic criteria with improved sensitivity and specificity

Classification criteria to identify subpopulations of SLE with distinct pathogenetic, clinical, and laboratory features and response to therapy

Diagnostic algorithms for neuropsychiatric lupus

Treatment

Indications and optimal targets for autologous stem-cell therapy in SLE

Major indications for biological therapies in SLE (B cell depletion, inhibition of B cell differentiation, costimulation blockade, toleragens)

Optimum management of membranous nephropathy

Options for resistant disease involving major and non-major organs

Indications, efficacy, toxicity of combined immunosuppressive and anticoagulant therapy for patients with antiphospholipid syndrome and SLE

Flares

Mechanisms of flare: residual vs sub-clinical disease vs de novo flare

Biomarkers for residual disease and for early relapse

Optimal management of flares

Comorbidities

Primary prevention of cardiovascular disease

Primary prevention and screening for osteoporosis

Strategies to increase compliance with therapy and preventive medicine

Strategies to decrease morbidity and mortality from infection

Validation of the Charlson Comorbidity score in SLE trials for optimal patient stratification

Neonatal lupus

Epidemiology, risk factors and management

Pregnancy

Impact of assisted fertilisation on disease activity

Effect of maternal immunosuppressive treatment on offspring long-term outcome

Antiphospholipid antibodies

Determine whether individuals with persistently positive antiphospholipid antibodies should receive prophylaxis (and type of) for thrombosis or pregnancy-related type morbidity

Recommended treatment for pregnant patients with APS who had pregnancy loss on low-dose aspirin and heparin

Paediatric and adolescent SLE

Epidemiology, optimal management and long-term outcome

Geriatric lupus

Epidemiology, optimal management and long-term outcome 
Modern immunosuppressive therapies are effective, but none of them cures lupus with approximately one-third of them flaring after remission. Initial management of moderate to severe flare requires induction therapy with immunosuppressive agents, which usually prevent the loss of renal function. ${ }^{134} 135$

\section{End-stage renal disease}

Despite recent advances in therapy of lupus nephritis, a number of patients may eventually progress to ESRD and will require dialysis treatment or even kidney transplantation. Both dialysis and transplantation in SLE have rates for long-term patient or graft survival comparable with those in non-diabetic/non-SLE patients. ${ }^{136-142}$ Antiphospholipid antibodies are associated with increased risk for thrombotic events, graft loss and poor transplantation outcome. ${ }^{106} 141143144$ There is no evidence from SLE-specific studies to support the superiority of either treatment option. Nonetheless, two retrospective studies including large numbers of patients with ESRD, have demonstrated superiority of renal transplantation over dialysis in terms of long-term patient survival (relative risk 0.19-0.32 at 12-18 months post-transplant). ${ }^{145} 146$

\section{DISCUSSION}

An initial set of statements and recommendations regarding important aspects of the management of SLE has been developed, based on systematic review of the literature and expert opinion with an excellent level of agreement among the experts (average 8.8 out of 10). These recommendations should facilitate the medical care of lupus patients without restricting the autonomy of the provider physicians who have the ultimate responsibility for the management.

Only a few RCTs have been performed to establish optimal management of SLE, and several important issues have not been adequately addressed. Furthermore, there are no RCTs to evaluate the effectiveness of lifestyle modifications and/or primary prevention interventions focused on SLE patients. These findings underscore the need to establish international networks to facilitate clinical trials addressing management issues and testing new therapies. To this end, the committee proposes a Research Agenda for the years to come (table 3).

Establishing a diagnosis and managing patients with SLE requires an integration of patient's symptoms, physical examination findings and the results of diagnostic testing. In the case of lupus, there are management issues with safety and financial implications that have not been addressed. There is a need to determine which laboratory tests should be performed at initial presentation and during follow-up of SLE patients, and how often. In the mean time, recommendations have to be based solely on expert opinion. The committee recommends examination and laboratory monitoring every 3 months, in patients who are doing well and more frequently for those with uncontrolled disease.

Clinical practice recommendations require a framework to assess their quality and to ensure that potential biases have been adequately addressed and are valid and feasible for practice. To this end, we used as a framework the Appraisal of Guidelines Research and Evaluation (AGREE) instrument, ${ }^{147}$ which rates six individual domains and 23 key items. Throughout the process, we made a conscientious effort to comply with as many of these as possible. Due to a paucity of strong data for several management issues, the development of review criteria for monitoring and/or audit purposes to measure the adherence to the recommendations is not feasible at this point. Moreover, we were not able to seek systematically patient views and preferences. Following this first round of recommendations, we intend to update them every 3 years with the inclusion of patients and individuals from other relevant professions and the development of tools that will facilitate the dissemination and application of the recommendations.

Acknowledgements: This work is dedicated to the memory of Dr Jose Font, a member of the committee. Support for this work was provided via a grant from the EULAR Excecutive Committee. We thank Dr Maxime Dougados for his encouragement, guidance and support. We also thank: (a) the staff of the EULAR House in Zurich (Fred and Elly Wyss, Robert Buff, and Ernst Isler and their associates) for their warm hospitality and outstanding organisation, (b) Mrs Natassa Mpizaki for expert secretarial assistance and (c) Drs Gabor Illei and Michael Ward for critical review of the manuscript. Dr George Bertsias is a graduate student of the Graduate Program in Molecular Basis of Human Disease (University of Crete School of Medicine).

Competing interests: None declared.

\section{REFERENCES}

1. Jonsson H, Nived O, Sturfelt G, Silman A. Estimating the incidence of systemic lupus erythematosus in a defined population using multiple sources of retrieval. Br J Rheumatol 1990;29:185-8.

2. Boumpas DT, Austin HA 3rd, Fessler BJ, Balow JE, Klippel JH, Lockshin MD. Systemic lupus erythematosus: emerging concepts. Part 1: Renal, neuropsychiatric, cardiovascular, pulmonary, and hematologic disease. Ann Intern Med 1995; 122:940-50.

3. Boumpas DT, Fessler BJ, Austin HA 3rd, Balow JE, Klippel JH, Lockshin MD. Systemic lupus erythematosus: emerging concepts. Part 2: Dermatologic and joint disease, the antiphospholipid antibody syndrome, pregnancy and hormonal therapy, morbidity and mortality, and pathogenesis. Ann Intern Med 1995;123:42-53.

4. Field MJ, Lohr KN, eds. Guidelines for clinical practice: from development to use. Washington, DC: National Academy Press, 1992.

5. Dougados M, Betteridge N, Burmester GR, Euller-Ziegler L, Guillemin F, Hirvonen J, et al. EULAR standardised operating procedures for the elaboration, evaluation, dissemination, and implementation of recommendations endorsed by the EULAR standing committees. Ann Rheum Dis 2004;63:1172-6.

6. Mok CC, Lee KW, Ho CT, Lau CS, Wong RW. A prospective study of survival and prognostic indicators of systemic lupus erythematosus in a southern Chinese population. Rheumatology (Oxford) 2000;39:399-406.

7. Mikdashi J, Handwerger B. Predictors of neuropsychiatric damage in systemic lupus erythematosus: data from the Maryland lupus cohort. Rheumatology (Oxford) 2004;43:1555-60.

8. Font J, Cervera R, Ramos-Casals M, Garcia-Carrasco M, Sents J, Herrero C, et al. Clusters of clinical and immunologic features in systemic lupus erythematosus: analysis of 600 patients from a single center. Semin Arthritis Rheum 2004;33:21730.

9. Alarcon GS, McGwin G Jr, Bastian HM, Roseman J, Lisse J, Fessler BJ, et al. Systemic lupus erythematosus in three ethnic groups. VII [correction of VIII]. Predictors of early mortality in the LUMINA cohort. LUMINA Study Group. Arthritis Rheum 2001;45:191-202.

10. Cervera R, Khamashta MA, Font J, Sebastiani GD, Gil A, Lavilla P, et al. Morbidity and mortality in systemic lupus erythematosus during a 10-year period: a comparison of early and late manifestations in a cohort of 1,000 patients. Medicine (Baltimore) 2003;82:299-308.

11. Manger K, Manger B, Repp R, Geisselbrecht M, Geiger A, Pfahlberg A, et al. Definition of risk factors for death, end stage renal disease, and thromboembolic events in a monocentric cohort of 338 patients with systemic lupus erythematosus. Ann Rheum Dis 2002;61:1065-70.

12. Austin HA 3rd, Boumpas DT, Vaughan EM, Balow JE. Predicting renal outcomes in severe lupus nephritis: contributions of clinical and histologic data. Kidney Int 1994:45:544-50.

13. Alarcon GS, McGwin G Jr, Bartolucci AA, Roseman J, Lisse J, Fessler BJ, et al Systemic lupus erythematosus in three ethnic groups. IX. Differences in damage accrual. Arthritis Rheum 2001;44:2797-806.

14. Petri M. Hopkins Lupus Cohort. 1999 update. Rheum Dis Clin North Am 2000;26:199-213.

15. Cook RJ, Gladman DD, Pericak D, Urowitz MB. Prediction of short term mortality in systemic lupus erythematosus with time dependent measures of disease activity. $J$ Rheumatol 2000;27:1892-5.

16. Vila LM, Alarcon GS, McGwin G Jr, Bastian HM, Fessler BJ, Reveille JD. Systemic lupus erythematosus in a multiethnic cohort (LUMINA): XXIX. Elevation of erythrocyte sedimentation rate is associated with disease activity and damage accrual. J Rheumatol 2005;32:2150-5.

17. Marto N, Bertolaccini ML, Calabuig E, Hughes GR, Khamashta MA. Anti-C1q antibodies in nephritis: correlation between titres and renal disease activity and positive predictive value in systemic lupus erythematosus. Ann Rheum Dis 2005:64:444-8. 
18. Alba P, Bento L, Cuadrado MJ, Karim Y, Tungekar MF, Abbs I, et al. Anti-dsDNA, anti-Sm antibodies, and the lupus anticoagulant: significant factors associated with lupus nephritis. Ann Rheum Dis 2003;62:556-60.

19. Ruiz-Irastorza G, Egurbide MV, Ugalde J, Aguirre C. High impact of antiphospholipid syndrome on irreversible organ damage and survival of patients with systemic lupus erythematosus. Arch Intern Med 2004;164:77-82.

20. Appenzeller S, Cendes F, Costallat LT. Epileptic seizures in systemic lupus erythematosus. Neurology 2004;63:1808-12.

21. Mond CB, Peterson MG, Rothfield NF. Correlation of anti-Ro antibody with photosensitivity rash in systemic lupus erythematosus patients. Arthritis Rheum 1989;32:202-4

22. Korbet SM, Lewis EJ, Schwartz MM, Reichlin M, Evans J, Rohde RD. Factors predictive of outcome in severe lupus nephritis. Lupus Nephritis Collaborative Study Group. Am J Kidney Dis 2000;35:904-14.

23. Karassa FB, loannidis JP, Boki KA, Touloumi G, Argyropoulou MI, Strigaris KA, et al. Predictors of clinical outcome and radiologic progression in patients with neuropsychiatric manifestations of systemic lupus erythematosus. Am J Med 2000;109:628-34.

24. Austin HA 3rd, Boumpas DT, Vaughan EM, Balow JE. High-risk features of lupus nephritis: importance of race and clinical and histological factors in 166 patients. Nephrol Dial Transplant 1995;10:1620-8.

25. Moroni G, Ventura D, Riva P, Panzeri P, Quaglini S, Banfi G, et al. Antiphospholipid antibodies are associated with an increased risk for chronic renal insufficiency in patients with lupus nephritis. Am J Kidney Dis 2004;43:28-36.

26. Urowitz MB, Gladman DD. Measures of disease activity and damage in SLE. Baillieres Clin Rheumatol 1998:12:405-13.

27. Strand V. Clinical trial design in systemic lupus erythematosus: lessons learned and future directions. Lupus 2004;13:406-11.

28. Stoll T, Sutcliffe N, Mach J, Klaghofer R, Isenberg DA. Analysis of the relationship between disease activity and damage in patients with systemic lupus erythematosus - a 5-yr prospective study. Rheumatology (Oxford) 2004;43:1039_

29. Stoll T, Stucki G, Malik J, Pyke S, Isenberg D. Further validation of the BILAG disease activity index in patients with systemic lupus erythematosus. Ann Rheum Dis 1996;55:756-60

30. Ward M, Marx A, Barry N. Comparison of the validity and sensitivity to change of 5 activity indices in systemic lupus erythematosus. J Rheumatol 2000;27:664-70.

31. Chang E, Abrahamowicz M, Ferland D, Fortin PR. Comparison of the responsiveness of lupus disease activity measures to changes in systemic lupus erythematosus activity relevant to patients and physicians. J Clin Epidemiol 2002;55:488-97.

32. Zecevic RD, Vojvodic D, Ristic B, Pavlovic MD, Stefanovic D, Karadaglic D. Skin lesions - an indicator of disease activity in systemic lupus erythematosus? Lupus 2001;10:364-7.

33. Mirzayan MJ, Schmidt RE, Witte T. Prognostic parameters for flare in systemic lupus erythematosus. Rheumatology (Oxford) 2000;39:1316-9.

34. Ziakas PD, Giannouli S, Zintzaras E, Tzioufas AG, Voulgarelis M. Lupus thrombocytopenia: clinical implications and prognostic significance. Ann Rheum Dis 2005;64:1366-9.

35. Ho A, Barr SG, Magder LS, Petri M. A decrease in complement is associated with increased renal and hematologic activity in patients with systemic lupus erythematosus. Arthritis Rheum 2001;44:2350-7.

36. Illei GG, Takada K, Parkin D, Austin HA, Crane M, Yarboro CH, et al. Renal flares are common in patients with severe proliferative lupus nephritis treated with pulse immunosuppressive therapy: long-term followup of a cohort of 145 patients participating in randomized controlled studies. Arthritis Rheum 2002:46:995-1002.

37. Ho A, Magder LS, Barr SG, Petri M. Decreases in anti-double-stranded DNA levels are associated with concurrent flares in patients with systemic lupus erythematosus. Arthritis Rheum 2001:44:2342-9.

38. Urowitz MB, Feletar M, Bruce IN, Ibanez D, Gladman DD. Prolonged remission in systemic lupus erythematosus. J Rheumatol 2005;32:1467-72.

39. Coremans IE, Spronk PE, Bootsma H, Daha MR, van der Voort EA, Kater L, et al. Changes in antibodies to $\mathrm{C} 1 \mathrm{q}$ predict renal relapses in systemic lupus erythematosus. Am J Kidney Dis 1995;26:595-601.

40. Swaak AJ, Groenwold J, Bronsveld W. Predictive value of complement profiles and anti-dsDNA in systemic lupus erythematosus. Ann Rheum Dis 1986;45:359-66.

41. ter Borg EJ, Horst G, Hummel E, Limburg PC, Kallenberg CG. Rises in anti-double stranded DNA antibody levels prior to exacerbations of systemic lupus erythematosus are not merely due to polyclonal B cell activation. Clin Immunol Immunopathol 1991:59:117-28.

42. Bootsma H, Spronk P, Derksen R, de Boer G, Wolters-Dicke H, Hermans J, et al. Prevention of relapses in systemic lupus erythematosus. Lancet 1995;345:1595-9.

43. Abu-Shakra M, Urowitz MB, Gladman DD, Gough J. Mortality studies in systemic lupus erythematosus. Results from a single center. II. Predictor variables for mortality. J Rheumatol 1995;22:1265-70.

44. Jacobsen S, Petersen J, Ullman S, Junker P, Voss A, Rasmussen JM, et al. Mortality and causes of death of 513 Danish patients with systemic lupus erythematosus. Scand J Rheumatol 1999;28:75-80.

45. Mok CC, Mak A, Chu WP, To CH, Wong SN. Long-term survival of southern Chinese patients with systemic lupus erythematosus: a prospective study of all age-groups. Medicine (Baltimore) 2005:84:218-24.

46. Hidalgo-Tenorio C, Jimenez-Alonso J, de Dios Luna J, Tallada M, Martinez-Brocal A, Sabio JM. Urinary tract infections and lupus erythematosus. Ann Rheum Dis 2004;63:431-7.
47. Bruce IN, Urowitz MB, Gladman DD, Ibanez D, Steiner G. Risk factors for coronary heart disease in women with systemic lupus erythematosus: the Toronto Risk Factor Study. Arthritis Rheum 2003;48:3159-67.

48. Asanuma Y, Oeser A, Shintani AK, Turner E, Olsen N, Fazio S, et al. Premature coronary-artery atherosclerosis in systemic lupus erythematosus. N Engl J Med 2003;349:2407-15.

49. Jimenez S, Garcia-Criado MA, Tassies D, Reverter JC, Cervera R, Gilabert MR, et al. Preclinical vascular disease in systemic lupus erythematosus and primary antiphospholipid syndrome. Rheumatology (Oxford) 2005:44:756-61.

50. Bjornadal L, Yin L, Granath F, Klareskog L, Ekbom A. Cardiovascular disease a hazard despite improved prognosis in patients with systemic lupus erythematosus: results from a Swedish population based study 1964-95. J Rheumatol 2004;31:713-9.

51. Gilboe IM, Kvien TK, Haugeberg G, Husby G. Bone mineral density in systemic lupus erythematosus: comparison with rheumatoid arthritis and healthy controls. Ann Rheum Dis 2000;59:110-5

52. Gladman DD, Urowitz MB, Chaudhry-Ahluwalia V, Hallet DC, Cook RJ. Predictive factors for symptomatic osteonecrosis in patients with systemic lupus erythematosus. J Rheumatol 2001;28:761-5.

53. Bernatsky S, Boivin JF, Joseph L, Rajan R, Zoma A, Manzi S, et al. An international cohort study of cancer in systemic lupus erythematosus. Arthritis Rheum 2005:52:1481-90.

54. Denburg SD, Carbotte RM, Denburg JA. Corticosteroids and neuropsychological functioning in patients with systemic lupus erythematosus. Arthritis Rheum 1994; 37:1311-20.

55. The Canadian Hydroxychloroquine Study Group. A randomized study of the effect of withdrawing hydroxychloroquine sulfate in systemic lupus erythematosus. N Engl J Med 1991;324:150-4.

56. Tsakonas E, Joseph L, Esdaile JM, Choquette D, Senecal JL, Cividino A, et al. A long-term study of hydroxychloroquine withdrawal on exacerbations in systemic lupus erythematosus. The Canadian Hydroxychloroquine Study Group. Lupus 1998;7:80-5.

57. Carneiro JR, Sato El. Double blind, randomized, placebo controlled clinical trial of methotrexate in systemic lupus erythematosus. J Rheumatol 1999;26:1275-9.

58. Ginzler E, Sharon E, Diamond H, Kaplan D. Long-term maintenance therapy with azathioprine in systemic lupus erythematosus. Arthritis Rheum 1975;18:27-34.

59. Sharon E, Kaplan D, Diamond HS. Exacerbation of systemic lupus erythematosus after withdrawal of azathioprine therapy. N Engl J Med 1973:288:122-4.

60. Stege H, Budde MA, Grether-Beck S, Krutmann J. Evaluation of the capacity of sunscreens to photoprotect lupus erythematosus patients by employing the photoprovocation test. Photodermatol Photoimmunol Photomed 2000;16:256-9.

61. Miyakis S, Lockshin M, Atsumi T, Branch DW, Brey RL, Cervera R, et al. International consesus statement on an update of the classification criteria for definite antiphospholipid syndrome (APS). J Thromb Haemostasis 2006;4:295-306.

62. Sambrook P, Birmingham J, Kelly P, Kempler S, Nguyen T, Pocock N, et al. Prevention of corticosteroid osteoporosis. A comparison of calcium, calcitriol, and calcitonin. N Engl J Med 1993;328:1747-52.

63. Adachi JD, Bensen WG, Bianchi F, Cividino A, Pillersdorf S, Sebaldt RJ, et al Vitamin $D$ and calcium in the prevention of corticosteroid induced osteoporosis: a 3 year followup. J Rheumatol 1996;23:995-1000

64. Nzeusseu Toukap A, Depresseux G, Devogelaer JP, Houssiau FA. Oral pamidronate prevents high-dose glucocorticoid-induced lumbar spine bone loss in premenopausal connective tissue disease (mainly lupus) patients. Lupus 2005; 14:517-20.

65. Oestensen M, Khamashta M, Lockshin M, Parke A, Brucato A, Carp H, et al. Antiinflammatory and immunosuppressive drugs and reproduction. Arthritis Res Ther 2006;8:209-28.

66. Sanchez-Guerrero J, Karlson EW, Liang MH, Hunter DJ, Speizer FE, Colditz GA. Past use of oral contraceptives and the risk of developing systemic lupus erythematosus. Arthritis Rheum 1997;40:804-8

67. Petri M, Kim MY, Kalunian KC, Grossman J, Hahn BH, Sammaritano LR, et al. Combined oral contraceptives in women with systemic lupus erythematosus. N Engl J Med 2005;353:2550-8.

68. Sanchez-Guerrero J, Uribe AG, Jimenez-Santana L, Mestanza-Peralta M, LaraReyes $P$, Seuc AH, et al. A trial of contraceptive methods in women with systemic lupus erythematosus. N Engl J Med 2005:353:2539-49.

69. Bhattoa HP, Bettembuk P, Balogh A, Szegedi G, Kiss E. The effect of 1-year transdermal estrogen replacement therapy on bone mineral density and biochemical markers of bone turnover in osteopenic postmenopausal systemic lupus erythematosus patients: a randomized, double-blind, placebo-controlled trial. Osteoporos Int 2004:15:396-404.

70. Buyon JP, Petri MA, Kim MY, Kalunian KC, Grossman J, Hahn BH, et al. The effect of combined estrogen and progesterone hormone replacement therapy on disease activity in systemic lupus erythematosus: a randomized trial. Ann Intern Med 2005; 142:953-62.

71. Mitsikostas DD, Sfikakis PP, Goadsby PJ. A meta-analysis for headache in systemic lupus erythematosus: the evidence and the myth. Brain 2004;127:1200-9.

72. Carlomagno S, Migliaresi S, Ambrosone L, Sannino M, Sanges G, Di lorio G. Cognitive impairment in systemic lupus erythematosus: a follow-up study. J Neurol 2000;247:273-9.

73. Monastero R, Bettini P, Del Zotto E, Cottini E, Tincani A, Balestrieri G, et al. Prevalence and pattern of cognitive impairment in systemic lupus erythematosus 
patients with and without overt neuropsychiatric manifestations. J Neurol Sci 2001;184:33-9.

74. West SG, Emlen W, Wener MH, Kotzin BL. Neuropsychiatric lupus erythematosus: a 10-year prospective study on the value of diagnostic tests. Am J Med 1995;99:153-63.

75. Ritchlin CT, Chabot RJ, Alper K, Buyon J, Belmont HM, Roubey R, et al. Quantitative electroencephalography. A new approach to the diagnosis of cerebral dysfunction in systemic lupus erythematosus. Arthritis Rheum 1992;35:1330-42.

76. Karassa FB, Afeltra A, Ambrozic A, Chang DM, De Keyser F, Doria A, et al. Accuracy of anti-ribosomal $P$ protein antibody testing for the diagnosis of neuropsychiatric systemic lupus erythematosus: an international meta-analysis. Arthritis Rheum 2006:54:312-24.

77. Kovacs JA, Urowitz MB, Gladman DD, Zeman R. The use of single photon emission computerized tomography in neuropsychiatric SLE: a pilot study. J Rheumatol 1995;22:1247-53

78. Jennings JE, Sundgren PC, Attwood J, McCune J, Maly P. Value of MRI of the brain in patients with systemic lupus erythematosus and neurologic disturbance. Neuroradiology 2004;46:15-21

79. Barile-Fabris L, Ariza-Andraca R, Olguin-Ortega L, Jara LJ, Fraga-Mouret A, Miranda-Limon JM, et al. Controlled clinical trial of IV cyclophosphamide versus IV methylprednisolone in severe neurological manifestations in systemic lupus erythematosus. Ann Rheum Dis 2005;64:620-5.

80. Mok CC, Lau CS, Chan EY, Wong RW. Acute transverse myelopathy in systemic lupus erythematosus: clinical presentation, treatment, and outcome. J Rheumatol 1998:25:467-73.

81. Stojanovich L, Stojanovich R, Kostich V, Dzjolich E. Neuropsychiatric lupus favourable response to low dose i.v. cyclophosphamide and prednisolone (pilot study). Lupus 2003;12:3-7.

82. Balasch J, Creus M, Fabregues F, Reverter JC, Carmona F, Tassies D, et al. Antiphospholipid antibodies and human reproductive failure. Hum Reprod 1996;11:2310-5.

83. Geva E, Lerner-Geva L, Burke M, Vardinon N, Lessing JB, Amit A. Undiagnosed systemic lupus erythematosus in a cohort of infertile women. Am J Reprod Immunol 2004;51:336-40.

84. Silva CA, Leal MM, Leone C, Simone VP, Takiuti AD, Saito MI, et al. Gonadal function in adolescents and young women with juvenile systemic lupus erythematosus. Lupus 2002;11:419-25.

85. Hayslett JP. The effect of systemic lupus erythematosus on pregnancy and pregnancy outcome. Am J Reprod Immunol 1992;28:199-204.

86. Petri M, Genovese M. Engle E. Hochberg M. Definition, incidence, and clinical description of flare in systemic lupus erythematosus. A prospective cohort study. Arthritis Rheum 1991;34:937-44.

87. Cortes-Hernandez J, Ordi-Ros J, Paredes F, Casellas M, Castillo F, Vilardell-Tarres M. Clinical predictors of fetal and maternal outcome in systemic lupus erythematosus: a prospective study of 103 pregnancies. Rheumatology (Oxford) 2002:41:643-50.

88. Nossent HC, Swaak TJ. Systemic lupus erythematosus. VI. Analysis of the interrelationship with pregnancy. J Rheumatol 1990;17:771-6.

89. Julkunen H, Kaaja R, Palosuo T, Gronhagen-Riska C, Teramo K. Pregnancy in lupus nephropathy. Acta Obstet Gynecol Scand 1993;72:258-63.

90. Carmona F, Font J, Azulay M, Creus M, Fabregues F, Cervera R, et al. Risk factors associated with fetal losses in treated antiphospholipid syndrome pregnancies: a multivariate analysis. Am J Reprod Immunol 2001:46:274-9.

91. Yasmeen S, Wilkins EE, Field NT, Sheikh RA, Gilbert WM. Pregnancy outcomes in women with systemic lupus erythematosus. J Matern Fetal Med 2001;10:91-6.

92. Moroni G, Ponticelli C. The risk of pregnancy in patients with lupus nephritis. J Nephrol 2003;16:161-7.

93. Hardy CJ, Palmer BP, Morton SJ, Muir KR, Powell RJ. Pregnancy outcome and family size in systemic lupus erythematosus: a case-control study. Rheumatology (Oxford) 1999;38:559-63

94. Julkunen H, Jouhikainen T, Kaaja R, Leirisalo-Repo M, Stephansson E, Palosuo T, et al. Fetal outcome in lupus pregnancy: a retrospective case-control study of 242 pregnancies in 112 patients. Lupus 1993;2:125-31

95. Mintz G, Niz J, Gutierrez G, Garcia-Alonso A, Karchmer S. Prospective study of pregnancy in systemic lupus erythematosus. Results of a multidisciplinary approach. J Rheumatol 1986:13:732-9.

96. Lockwood CJ, Romero R, Feinberg RF, Clyne LP, Coster B, Hobbins JC. The prevalence and biologic significance of lupus anticoagulant and anticardiolipin antibodies in a general obstetric population. Am J Obstet Gynecol 1989;161:369_ 73.

97. Polzin WJ, Kopelman JN, Robinson RD, Read JA, Brady K. The association of antiphospholipid antibodies with pregnancies complicated by fetal growth restriction. Obstet Gynecol 1991;78:1108-11

98. Buyon JP, Hiebert R, Copel J, Craft J, Friedman D, Katholi M, et al. Autoimmuneassociated congenital heart block: demographics, mortality, morbidity and recurrence rates obtained from a national neonatal lupus registry. J Am Coll Cardiol 1998:31:1658-66.

99. Le Thi Huong D, Wechsler B, Piette JC, Bletry 0, Godeau P. Pregnancy and its outcome in systemic lupus erythematosus. OJM 1994:87:721-9.

100. Levy RA, Vilela VS, Cataldo MJ, Ramos RC, Duarte JL, Tura BR, et al. Hydroxychloroquine (HCO) in lupus pregnancy: double-blind and placebo-controlled study. Lupus 2001:10:401-4.
101. Ramsey-Goldman R, Mientus JM, Kutzer JE, Mulvihill JJ, Medsger TA Jr. Pregnancy outcome in women with systemic lupus erythematosus treated with immunosuppressive drugs. J Rheumatol 1993;20:1152-7.

102. Ramsey-Goldman R, Schilling E. Immunosuppressive drug use during pregnancy. Rheum Dis Clin North Am 1997;23:149-67.

103. Khamashta MA, Cuadrado MJ, Mujic F, Taub NA, Hunt BJ, Hughes GR. The management of thrombosis in the antiphospholipid-antibody syndrome. N Engl J Med 1995:332:993-7.

104. Munoz-Rodriguez FJ, Font J, Cervera R, Reverter JC, Tassies D, Espinosa G, et al Clinical study and follow-up of 100 patients with the antiphospholipid syndrome. Semin Arthritis Rheum 1999;29:182-90.

105. Ruiz-Irastorza G, Khamashta MA, Hunt BJ, Escudero A, Cuadrado MJ, Hughes GR Bleeding and recurrent thrombosis in definite antiphospholipid syndrome: analysis of a series of 66 patients treated with oral anticoagulation to a target international normalized ratio of 3.5. Arch Intern Med 2002;162:1164-9.

106. Vaidya S, Sellers R, Kimball P, Shanahan T, Gitomer J, Gugliuzza K, et al. Frequency, potential risk and therapeutic intervention in end-stage renal disease patients with antiphospholipid antibody syndrome: a multicenter study. Transplantation 2000;69:1348-52

107. Crowther MA, Ginsberg JS, Julian J, Denburg J, Hirsh J, Douketis J, et al. A comparison of two intensities of warfarin for the prevention of recurrent thrombosis in patients with the antiphospholipid antibody syndrome. N Engl J Med 2003;349:1133-8.

108. Finazzi G, Marchioli R, Brancaccio V, Schinco P, Wisloff F, Musial J, et al. A randomized clinical trial of high-intensity warfarin vs. conventional antithrombotic therapy for the prevention of recurrent thrombosis in patients with the antiphospholipid syndrome (WAPS). J Thromb Haemost 2005;3:848-53.

109. Rivier G, Herranz MT, Khamashta MA, Hughes GR. Thrombosis and antiphospholipid syndrome: a preliminary assessment of three antithrombotic treatments. Lupus 1994;3:85-90.

110. Rosove MH, Brewer PM. Antiphospholipid thrombosis: clinical course after the firs thrombotic event in 70 patients. Ann Intern Med 1992;117:303-8.

111. Empson M, Lassere M, Craig J, Scott J. Prevention of recurrent miscarriage for women with antiphospholipid antibody or lupus anticoagulant. Cochrane Database Syst Rev 2005:CD002859

112. Baldwin DS, Gluck MC, Lowenstein J, Gallo GR. Lupus nephritis. Clinical course as related to morphologic forms and their transitions. Am J Med 1977;62:12-30.

113. Balow JE, Austin HA 3rd, Muenz LR, Joyce KM, Antonovych TT, Klippel JH, et al. Effect of treatment on the evolution of renal abnormalities in lupus nephritis. N Engl J Med 1984;311:491-5.

114. Hill GS, Delahousse M, Nochy D, Thervet E, Vrtovsnik F, Remy P, et al. Outcome of relapse in lupus nephritis: roles of reversal of renal fibrosis and response of inflammation to therapy. Kidney Int 2002;61:2176-86.

115. Rahman A, Gladman D, Ibanez D, Urowitz M. Significance of isolated hematuria and isolated puyria in systemic lupus erythematosus. J Rheumatol 2000;10:418-23.

116. Hebert LA, Dillon JJ, Middendorf DF, Lewis EJ, Peter JB. Relationship between appearance of urinary red blood cell/white blood cell casts and the onset of renal relapse in systemic lupus erythematosus. Am J Kidney Dis 1995;26:432-8.

117. Houssiau FA, Vasconcelos C, D'Cruz D, Sebastiani GD, de Ramon Garrido E, Danieli $M G$, et al. Early response to immunosuppressive therapy predicts good renal outcome in lupus nephritis: lessons from long-term followup of patients in the EuroLupus Nephritis Trial. Arthritis Rheum 2004;50:3934-40.

118. Cortes-Hernandez J, Ordi-Ros J, Labrador M, Segarra A, Tovar JL, Balada E, et al. Predictors of poor renal outcome in patients with lupus nephritis treated with combined pulses of cyclophosphamide and methylprednisolone. Lupus 2003:12:287-96

119. Gourley MF, Austin HA 3rd, Scott D, Yarboro CH, Vaughan EM, Muir J, et al. Methylprednisolone and cyclophosphamide, alone or in combination, in patients with lupus nephritis. A randomized, controlled trial. Ann Intern Med 1996:125:549-57.

120. Flanc RS, Roberts MA, Strippoli GF, Chadban SJ, Kerr PG, Atkins RC. Treatment for lupus nephritis. Cochrane Database Syst Rev 2004:CD002922.

121. Flanc RS, Roberts MA, Strippoli GF, Chadban SJ, Kerr PG, Atkins RC. Treatment of diffuse proliferative lupus nephritis: a meta-analysis of randomized controlled trials. Am J Kidney Dis 2004;43:197-208.

122. Austin HA 3rd, Klippel JH, Balow JE, le Riche NG, Steinberg AD, Plotz PH, et al Therapy of lupus nephritis. Controlled trial of prednisone and cytotoxic drugs. N Engl J Med 1986;314:614-9.

123. Illei GG, Austin HA, Crane M, Collins L, Gourley MF, Yarboro CH, et al Combination therapy with pulse cyclophosphamide plus pulse methylprednisolone improves longterm renal outcome without adding toxicity in patients with lupus nephritis. Ann Intern Med 2001:135:248-57.

124. Boumpas DT, Austin HA 3rd, Vaughn EM, Klippel JH, Steinberg AD, Yarboro CH, et al. Controlled trial of pulse methylprednisolone versus two regimens of pulse cyclophosphamide in severe lupus nephritis. Lancet 1992;340(8822):741-5.

125. Somers EC, Marder W, Christman GM, Ognenovski V, McCune WJ. Use of a gonadotropin-releasing hormone analog for protection against premature ovarian failure during cyclophosphamide therapy in women with severe lupus. Arthritis Rheum 2005:52:2761-7.

126. Chan TM, Li FK, Tang CS, Wong RW, Fang GX, Ji YL, et al. Efficacy of mycophenolate mofetil in patients with diffuse proliferative lupus nephritis. Hong Kong-Guangzhou Nephrology Study Group. N Engl J Med 2000;343:1156-62. 
127. Chan TM, Tse KC, Tang CS, Mok MY, Li FK. Long-term study of mycophenolate mofetil as continuous induction and maintenance treatment for diffuse proliferative lupus nephritis. J Am Soc Nephrol 2005;16:1076-84.

128. Ginzler EM, Dooley MA, Aranow C, Kim MY, Buyon J, Merrill JT, et al. Mycophenolate mofetil or intravenous cyclophosphamide for lupus nephritis. N Engl J Med 2005;353:2219-28.

129. Ong LM, Hooi LS, Lim TO, Goh BL, Ahmad G, Ghazalli R, et al. Randomized controlled trial of pulse intravenous cyclophosphamide versus mycophenolate mofetil in the induction therapy of proliferative lupus nephritis. Nephrology (Carlton) 2005; 10:504-10.

130. Contreras G, Pardo V, Leclercq B, Lenz O, Tozman E, O'Nan P, et al. Sequential therapies for proliferative lupus nephritis. N Engl J Med 2004;350:971-80.

131. Liang MH, Schur PH, Fortin PJ, St Clair EW, Ballow JE, Costenbader KH, et al. The American college of rheumatology response criteria for proliferative and membranous renal disease in systemic lupus erythematosus clinical trials. Arthritis Rheum 2006;54:421-32.

132. van Vollenhoven R, Gunnarsson I. In lupus nephritis, the benefit of rituximab monotherapy, as opposed to rituximab plus cyclophosphamide combination therapy, remains uncertain: comment on the article by Sfikakis et al. Arthritis Rheum 2005;52:4050-1 [author reply 1-2].

133. Leandro MJ, Cambridge G, Edwards JC, Ehrenstein MR, Isenberg DA. B-cell depletion in the treatment of patients with systemic lupus erythematosus: a longitudinal analysis of 24 patients. Rheumatology (Oxford) 2005:44:1542-5.

134. Ioannidis JP, Boki KA, Katsorida ME, Drosos AA, Skopouli FN, Boletis JN, et al Remission, relapse, and re-remission of proliferative lupus nephritis treated with cyclophosphamide. Kidney Int 2000:57:258-64.

135. Sidiropoulos PI, Kritikos HD, Boumpas DT. Lupus nephritis flares. Lupus 2005; 14:49-52.

136. Mojcik CF, Klippel JH. End-stage renal disease and systemic lupus erythematosus. Am J Med 1996;101:100-7.
137. Hellerstedt WL, Johnson WJ, Ascher N, Kjellstrand CM, Knutson R, Shapiro FL, et al. Survival rates of 2,728 patients with end-stage renal disease. Mayo Clin Proc 1984;59:776-83

138. Jarrett MP, Santhanam S, Del Greco F. The clinical course of end-stage renal disease in systemic lupus erythematosus. Arch Intern Med 1983;143:1353-6.

139. Bartosh SM, Fine RN, Sullivan EK. Outcome after transplantation of young patients with systemic lupus erythematosus: a report of the North American pediatric renal transplant cooperative study. Transplantation 2001;72:973-8.

140. Deegens JK, Artz MA, Hoitsma AJ, Wetzels JF. Outcome of renal transplantation in patients with systemic lupus erythematosus. Transpl Int 2003;16:411-8.

141. Moroni G, Tantardini F, Gallelli B, Quaglini S, Banfi G, Poli F, et al. The long-term prognosis of renal transplantation in patients with lupus nephritis. Am J Kidney Dis 2005;45:903-11.

142. Ward MM. Outcomes of renal transplantation among patients with end-stage renal disease caused by lupus nephritis. Kidney Int 2000:57:2136-43.

143. Collier JD, Sale J, Friend PJ, Jamieson NV, Calne RY, Alexander GJ. Graft loss and the antiphospholipid syndrome following liver transplantation. J Hepatol 1998;29:999-1003.

144. Fabrizi F, Sangiorgio R, Pontoriero G, Corti M, Tentori F, Troina E, et al. Antiphospholipid (aPL) antibodies in end-stage renal disease. J Nephrol 1999;12:89-94.

145. McDonald SP, Russ GR. Survival of recipients of cadaveric kidney transplants compared with those receiving dialysis treatment in Australia and New Zealand, 1991-2001. Nephrol Dial Transplant 2002;17:2212-9.

146. Wolfe RA, Ashby VB, Milford EL, Ojo A0, Ettenger RE, Agodoa LY, et al. Comparison of mortality in all patients on dialysis, patients on dialysis awaiting transplantation, and recipients of a first cadaveric transplant. N Engl J Med 1999;341:1725-30.

147. Appraisal of Guidelines for Research \& Evaluation. AGREE Instrument. The AGREE collaboration. 2001. http://www.agreecollaboration.com laccessed 15 Sep 2007).

\section{IOF-Servier 2008 Young Investigator Research Award}

The IOF-Servier Young Investigator Research Award, presented every two years to an osteoporosis researcher under the age of 40 , aims to encourage young scientists to carry out high quality research. The Award is supported by the Servier Research group in partnership with IOF, and awards 40000 Euros towards original research of significant value and international relevance in the field of osteoporosis. The project must contribute to ensuring that people with osteoporosis receive the best care possible.

Applications for the IOF-Servier 2008 Young Investigator Research Award are being accepted until 3 March 2008. The next grant will be presented at the IOF World Congress on Osteoporosis in December 2008.

http://www.iofbonehealth.org/health-professionals/iof-grants-awards.html 